\title{
Development of a thermal desorption method for the analysis of particle associated polycyclic aromatic hydrocarbons in ambient air
}

\author{
${ }^{I^{*}}$ A. R. Bahrami, ${ }^{1}$ I. Mohammad Fam and ${ }^{2}$ J. Donaldson \\ ${ }^{l}$ Department of Occupational Health, Hammadan University of Medical Science, Hammadan, Iran \\ ${ }^{2}$ Centre for Environmental Chemistry, Brunel University, Uxbridge, Middlesex, UB8 3PH, UK
}

\begin{abstract}
An investigation for the analysis of polycyclic aromatic hydrocarbons in airborne particulates using thermal desorption and gas chromatography-mass spectrometry is described. Samples are obtained from ambient air using fibreglass filters and the volatile material from the filter is thermally desorbed to gas chromatograph. A 30 meter capillary column is used to separate the hydrocarbons and eight polyaromatic hydrocarbons are used to test the method and recovery is $>95 \%$. The eight polycyclic aromatic hydrocarbons anthracene, phenanthrene, fluoranthrene, pyrene, benzo (a) anthracene, chrysene, benzo (a) pyrene and benzo (e) pyrene were the most abundant PAHs found in the samples of ambient air with current method at Uxbridge-London. Application of the measurement of polycyclic aromatic hydrocarbons in ambient air samples shows that the hydrocarbons trapped in the particle phase to a lesser degree at higher ambient temperature. In conclusion a method has been developed to transfer the PAHs in particle phase from a filter to GC-MS by thermal desorption. A standard mixture of PAHs, when absorbed onto the filter, did lead to strong analyte absorbent interactions by the high percent recovery of the sample.
\end{abstract}

Key words: Polycyclic aromatic hydrocarbons, ambient air, thermal desorption, gas chromatography, mass spectrometry

*Corresponding Author, E-mail: Bahrami@umsha.ac.ir

\section{Introduction}

Polycyclic aromatic hydrocarbons (PAHs) and their derivatives are widespread harmful compounds generated by incomplete combustion of organic material emitted from a large variety of industrial processes, motor vehicles and residential heating. Motor vehicles are thought to be the major source of atmospheric PAHs. PAHs occur in particles (Bodzek, et al., 1994) or in the vapour phase and are often emitted into the atmosphere (Fromme, et al., 1998 and Nielsen, et al., 1996). Some of these compounds eg benzo (a) pyrene have been classified as carcinogenic and mutagenic materials (Dipple, et al., 1999 and Wei, et al., 1996). Because of the wide range of vapor pressures of PAHs, some are exclusively in the gas phase in the atmosphere while others are adsorbed on particulate matter (Noto, et al., 1996). Several different analytical methods and sampling procedures have been described for the determination of PAHs in air. The most common sampling method involves pumping the air stream through a sample device (active sampling) fitted with a glass fiber filter device, which permits high flow rates. Compounds are then extracted from the filter with a solvent and the PAHs analyzed by high performance liquid chromatography with a fluorescence detector, by gas chromatography with a flame ionization detector, or by gas chromatography-mass spectrometry (Dabek-Zlotorzynska, et al., 1996, Bjrseth, 1985, Marvin, et al., 1999 and Hansen, et al., 1991). Due to their volatility, losses of PAHs during extraction are unavoidable and extraction with solvents is not a sensitive method because it dilutes the sample. Other disadvantages of extraction with solvents are the potential toxicity of the solvent and the instability of samples during storage. Recovery of PAHs (Hansen, et al., 1991) by any extraction method is about 80 percent and as a consequence there can be failure to detect some compounds. The study describes a procedure for the determination of PAHs in air at particulate phase with thermal desorbtion 
that is more sensitive and gives a higher recovery of analyt than the solvent extraction method. The study has been performed in London in 1999.

\section{Materials and Methods}

An EPA 525 solvent standard of PAHs was used as standard sample. Helium, dry Air. A sampling pump model Dyma MI 1A connected to a filter holder with a teflon tube was used to obtain samples of particulate. Calibration and adjustment of the sampling flow rates was achieved using a flow meter connected between the sampler and the pump. A glass fiber filters with $3.7 \mathrm{~cm}$ diameter and $0.2-\mu \mathrm{m}$ pore sizes were used to trap samples of particulates in air. The Thermal Desorption Model 890/891 was used to recover samples from filter and transfer to GC-MS. An empty tube was used to hold the filter in thermal desorption. A MD800 GC- mass spectrometer, with a $30 \mathrm{~m} \times 0.25 \mathrm{~mm}, 0.25$ $\mu \mathrm{m}$ film capillary column was used for the separation and identification of polycyclic aromatic hydrocarbons. This column was coated with poly (5\% diphenyl/ 95\% dimethylsiloxane) which permits can be used up $320^{\circ} \mathrm{C}$. GC achieved the separation of the hydrocarbons and each component was scanned in the mass spectrometer as it was eluted from the column. The lab - base software from fisons was used to obtain a chromatogram from the total ion current. Each peak in the chromatogram was identified by automatically comparing the MS scan with those in the database. Weather monitor from Davis Company was used for measurement of temperature, humidity, barometric pressure, and wind speed and wind direction in the field trials of the method.

\section{Analytical procedure}

A known volume of air was drawn through a fiberglass filter by means of a sampling pump; the fiberglass filter was cut into small pieces and placed in an empty tube of two stages thermal desorption. The thermal desorption unit was set at optimum conditions of temperature, flow rate and length of time which are $340{ }^{\circ} \mathrm{C}, 12-16 \mathrm{ml} / \mathrm{min}$ and $13-17$ minutes. Compounds were transferred to a GC column in an oven and heated from $70{ }^{\circ} \mathrm{C}$ to $300{ }^{\circ} \mathrm{C}$ at a rate of $7{ }^{\circ} \mathrm{C} \mathrm{min}^{-1}$. The outlet of the GC column was connected to a quadrupole mass spectrometer for PAHs analysis. The chromatogram and mass spectrum of each component of the chromatogram was saved in computer format. Figure 1 shows the gas chromatogram of a sample taken in ambient air. The identifycation number of each scan is shown above the appropriate peak. The software in the system can compare each peak in the spectrum with the spectra of sixty two thousand compounds that are stored in the software library. Figure 2 shows the mass spectrum of scan number 1376 of the chromatogram in Figure 1. Quantitative information was obtained from the area of the chromatogram peaks; areas were calibrated by injection of known amounts of a standard solution of 12 PAHs (EPA Supelco UK). Background corrections were made by performing the desorption procedure with a new unused fiberglass filter.

\section{Test of method}

To determine the analytical efficiency of procedure two experimental were done;

\section{Static test}

$1-\mu 1$ samples of specified amounts of mixed PAHs were added to a filter, filter store in freezer, after 1-4 hour each filter thermally desorbed into the GCMS. This analysis was performed 24 times.

\section{Test of method in ambient air}

To test the method for qualitative and quantitative analysis of PAHs, 55 samples of atmospheric particulate were collected on Uxbridge with fiberglass filters from ambient air at Uxbridge (west of London). The sampling was performed over 4 months and samples were collected at ground level and at 3 meters above ground level during the period, 09:00-17:00 hours, on working days. The average traffic densities covered the range 1000 vehicles/hour to 1400 vehicles/hour depending on the time of measurement. Samples were transferred directly to the laboratory for analysis. Several unexposed filters were analyzed to obtain baseline data. The wind speed at the sampling location covered the range $0-4.4 \mathrm{~m} \mathrm{~s}^{-1}$ over the sampling period.

\section{Results}

The results of static test were shown in Table 1 and indicate recoveries of PAHs were between 95 to $99.6 \%$ that high recovery. The 
International Journal of Environmental Science \& Technology

Vol. 1, No. 3, pp. 165-169, Autumn 2004

benzo(a)pyrene has more recovery than other compounds with $99.6 \%$ and benzo(e)pyrene 

Table 1: Recovery of PAHs from the analytical system

\begin{tabular}{|lccc|}
\hline \multicolumn{1}{|c|}{ Component } & $\begin{array}{c}\text { Concentration in } \\
\text { standard } \\
\text { solution }(\mu \mathrm{g} / \mu \mathrm{l})\end{array}$ & $\begin{array}{c}\text { The mean of } \\
\text { recovery } \\
\text { from filter }(\mu \mathrm{g} / \mu \mathrm{l})\end{array}$ & $\begin{array}{c}\text { Recovery } \\
(\%)\end{array}$ \\
\hline Phenanthrene & 0.5 & 0.483 & 96.6 \\
\hline Anthracene & 0.5 & 0.484 & 96.8 \\
\hline Fluoranthrene & 0.5 & 0.477 & 95.4 \\
\hline Pyrene & 0.5 & 0.495 & 98.8 \\
\hline Benzo (a) anthracene & 0.5 & 0.477 & 95.4 \\
\hline Chrysene & 0.5 & 0.491 & 98.2 \\
\hline Benzo (a) pyrene & 0.5 & 0.498 & 99.6 \\
\hline Benzo (e) pyrene & 0.5 & 0.476 & 95.2 \\
\hline
\end{tabular}

has less recovery with $95.2 \%$. The mean recovery concentration was $97 \pm 1.69$.

These results were provided under passing of specified amounts of mixed pure PAHs from filter. The eight polycyclic aromatic hydrocarbons anthracene, phenanthrene, fluoranthrene, pyrene, benzo(a)anthracene, chrysene, benzo(a)pyrene and benzo(e)pyrene were the most abundant PAHs found in the samples of ambient air. Most of the particulate sampled contained all the eight PAHs. Concentration of polycyclic aromatic hydrocarbons in ambient air over April to July was shown in Table 2.

Table 2: Concentration of polycyclic aromatic hydrocarbons $\left(\mathrm{ng} \mathrm{m}^{-3}\right)$ in ambient air over April to July 1997

\begin{tabular}{|lcccc|}
\hline \multicolumn{1}{|c}{ Compounds } & April & May & June & July \\
\hline Phenanthrene & 17.56 & 10.24 & 5.34 & 5.61 \\
\hline Anthracene & 4.64 & 2.43 & 1.71 & 1.17 \\
\hline Fluoranthrene & 21.53 & 15.17 & 14.70 & 9.64 \\
\hline Pyrene & 19.21 & 13.24 & 8.38 & 5.76 \\
\hline $\begin{array}{l}\text { Benzo(a) } \\
\text { anthracene }\end{array}$ & 6.41 & 6.34 & 3.97 & 2.91 \\
\hline Chrysene & 5.36 & 4.34 & 3.40 & 2.46 \\
\hline $\begin{array}{l}\text { Benzo(a) } \\
\text { pyre }\end{array}$ & 2.43 & 2.10 & 1.78 & 1.35 \\
\hline $\begin{array}{l}\text { Benzo(e) } \\
\text { pyrene }\end{array}$ & 2.14 & 1.80 & 1.96 & 1.22 \\
\hline
\end{tabular}

The concentration of fluoranthrene and pyrene were 21.53 and $19.21 \mathrm{ng} \mathrm{m}^{-3}$ respectively in April that was more than other aromatic hydrocarbons. The least concentration was found for benzo(e)pyrene $2.14 \mathrm{ng} \mathrm{m}^{-3}$. The field data show there was a significant drop in the amount of the hydrocarbons determined in June and July was found compared to the April-May period. The mean concentration of phenanthrene, anthracene, fluoranthrene, pyrene, benzo (a) anthracene, chrysene, benzo (a) pyrene, benzo (e) pyrene in April were $3.13,3.97,2.23,3.34,2.20,2.18,1.80,1.75$ times higher than July. The ratios of concentration of phenanthrene, anthracene, fluoranthrene, pyrene, benzo (a) anthracene, chrysene, benzo (a) pyrene, benzo (e) pyrene between April to June are 3.28, 2.71, 1.46, $2.29,1.61,1.57,1.36$, and 1.09 respectively.

\section{Discussion and Conclusion}

The result of this study was shown high recovery of PAHs in the static test and the samples were prepared and transferred from thermal desorption to GC at short time. The current method for preparation of sample is Sox let desorption that need to 12 to 24 hour for extraction of PAHs from filter whereas in two stages thermal desorption PAHs extracts from filter over 9 minute at $370{ }^{\circ} \mathrm{C}$ and transfer to GC-MS. Losses of the volatile PAHs during extraction with a solvent in soxlet desorption are unavoidable and consequent dilution of the sample reduces the reliability of the method. Other disadvantages of extractions with solvents are instability of samples during storage. Quantitative recovery of PAHs by any solvent extraction method is about 80-95 percent and as a consequence there can be a failure to detect some of the compounds. The results were shown the distribution PAHs in June and July was less than April-May. This is consistent with the more volatile PAHs (MW> 250) determined in April samples being adsorbed on particles, while in June and July, the same hydrocarbons are predominantly in the gas phase and not the particle phase. 


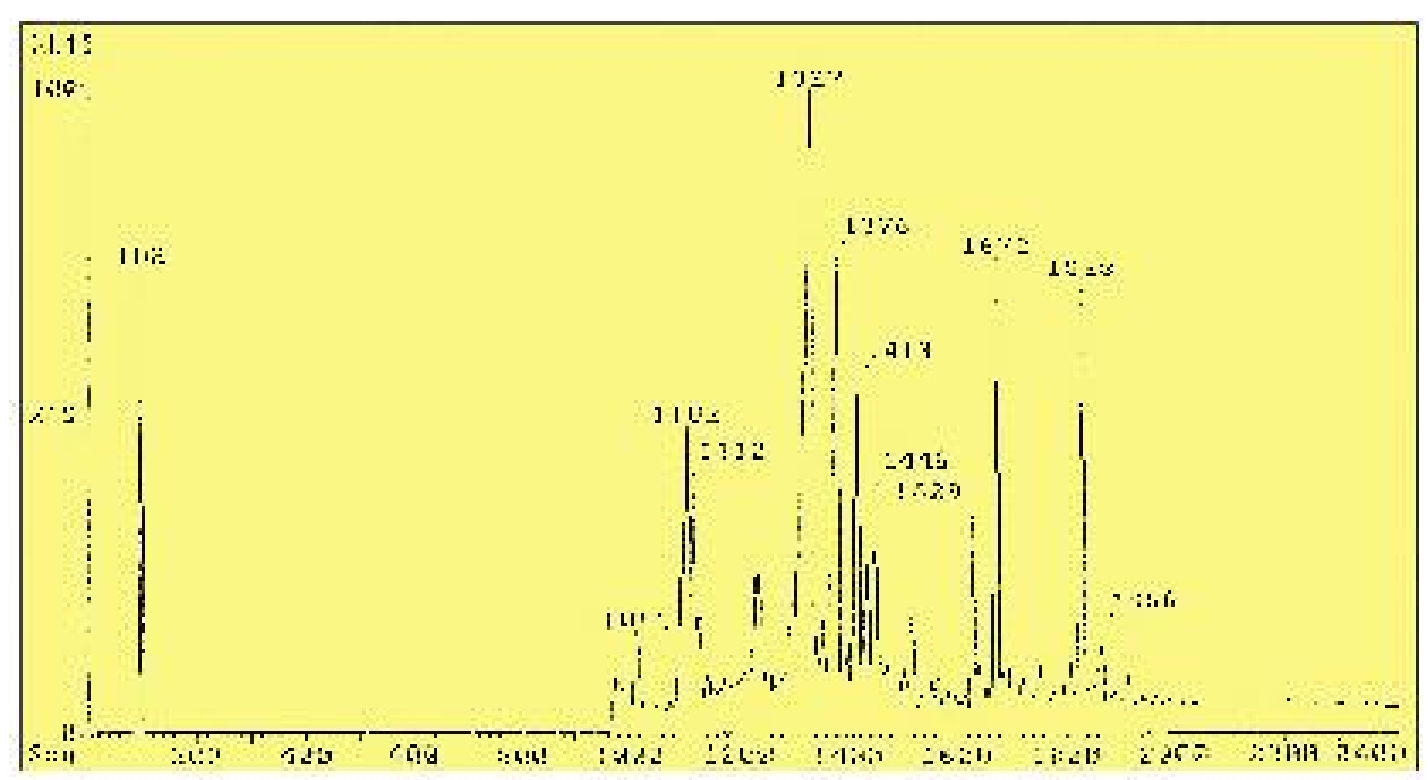

Figure 1: Gas chromatogram of a sample in atmospheric air

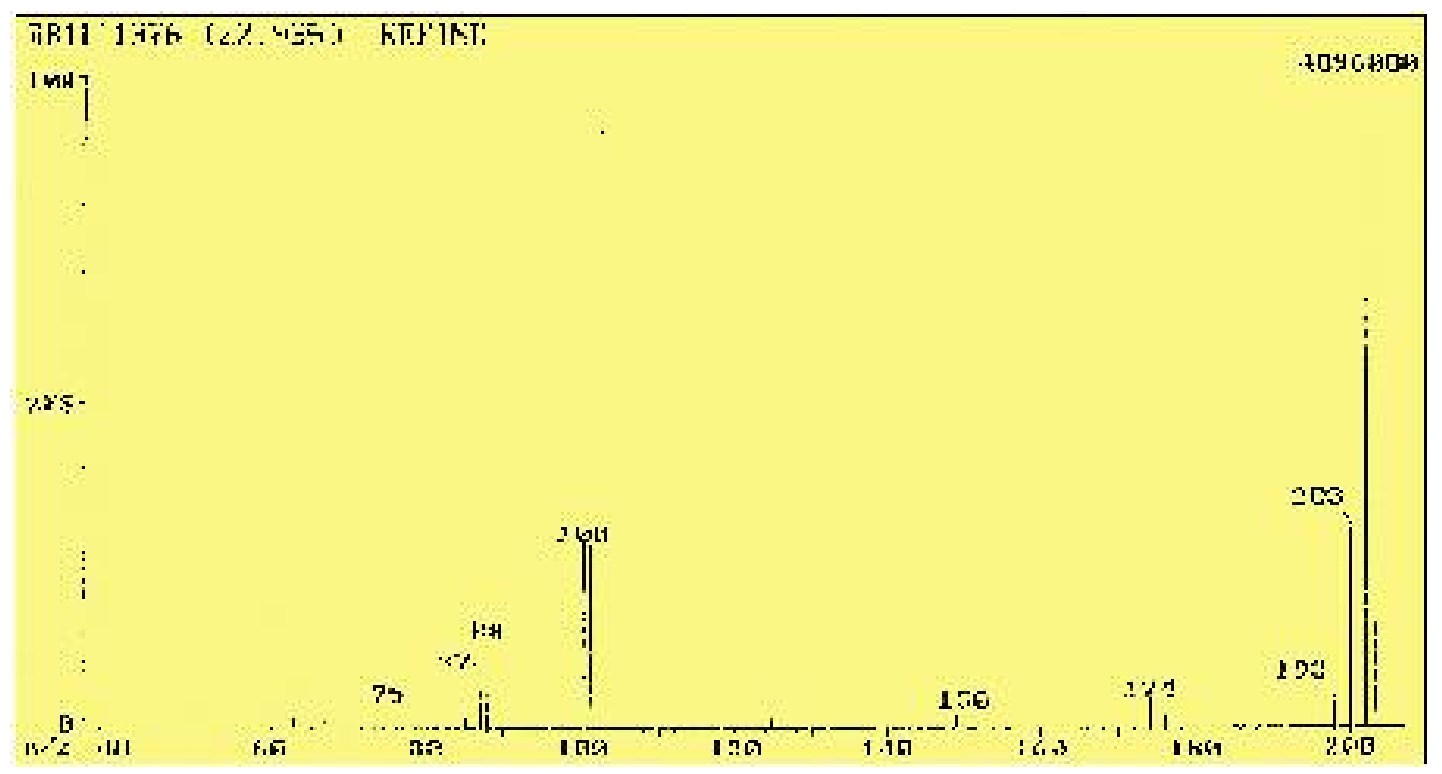

Figure 2: The mass spectrum of scan number 1376 of the chromatogram in Figure 1

The distribution of PAHs between gas and particle phases is dependent on temperature, air humidity, property of adsorption surface adsorption surface available, molecular weight and vapor pressure of PAHs In conclusion a method has been developed to transfer the PAHs from a filter to GC-MS by thermal desorption. A standard mixture of PAHs, when absorbed onto the filter, did lead to strong analyte absorbent interactions by the high percent recovery of the sample. A wide range of PAHs can be transferred from the filter giving high sample efficiency in a short time.
Development of thermal desorption for transfer compounds from filter to GC-MS overcome the disadvantages of liquid desorption.

\section{References}

Bjrseth, A., Handbook of polycyclic aromatic hydrocarbons. Dekker, New York, 1: 32-42 1985

Bodzek, D., B. Luks-Betlej and L. Warzecha, Determination of particle-associated polycyclic aromatic hydrocarbons in ambient air sampls from the upper silesia region of Poland. Atmos. Environ. 27A (5): 759-764, 1993 
Dabek-Zlotorzynska, E. and E. P. Lai, Seperation of polynuclear aromatic hydrocarbons by micellar electro kinetic capillary chromatography using sodium taurodeoxycholate modified with organic solvents. J. Capillary Electrophor, 3 (1), 31-35, 1996

Dipple, A., O. A. Khan, J. E. Page, I. Ponten and J. Szeliga, DNA reaction, mutagenic action and stealth properties of polycyclic aromatic hydrocarbon carcinogens. Int. J. Oncol. 14 (1): 103-111, 1999

Fromme, H., A. Oddoy, M. Piloty, M. Krause and T. Lahrz, Polycyclic aromatic hydrocarbons (PAH) and diesel engine emission (elemental carbon) incide a car and a subway train. Sci. Total Environ., 217: 165-173,1998

Hansen, A., I. Olsent, E. Holst and O. Poulsen, Validation of a high performance liquid chromatography/fluorescence detection method for the simulataneous quantification of fifteen polycyclic aromatic hydrocarbons. Ann. Occup. Hyg. 35 (6): 603-611, 1991
Marvin, C. H., R. W. Smith, D. W. Bryant and B. E. McCarry, Analysis of high-molecular-mass polycyclic aromatic hydrocarbons in environmental samples using liquid chromatography-atmospheric pressure chemical ionization mass spectrometry. J Chromatogr. A. 863 (1): 13-24, 1999

Nielsen, T., H. Jorgensen, J. Larsen and $M$. Poulsen, City air pollution of polycyclic aromatic hydrocarbons and other mutagens: occurrence, sources and health effects. Sci. Total Environ. 189-190, 41-49, 1996

Noto, H., K. Halgard, H. Daae, R. Bentsen and W. Eduard, Comparative study of an inhalable and a total dust sampler for personal sampling of dust and polycyclic aromatic hydrocarbons in the gas and particulate phase. Analyst. 121 (9): 11911196, 1996

Wei, O., J. Gu, L. Cheng, M. Bondy, H. Jiang, W. Hong and M. Spite, Benzo (a) pyrene diol epoxide-induced chromosomal aberrations and risk of lung cancer. Cancer Res. 56 (17): $3975-$ 3979, 1996 
